\title{
Resonance Analysis and Vibration Reduction Optimization of Agricultural Machinery Frame-Taking Vegetable Precision Seeder as an Example
}

\author{
Jinwu Wang (D), Changsu Xu, Yanan Xu, Jinfeng Wang, Wenqi Zhou, Qi Wang and Han Tang *D \\ College of Engineering, Northeast Agricultural University, Harbin 150030, China; jinwuw@neau.edu.cn (J.W.); \\ ChangsuXu@neau.edu.cn (C.X.); YananXu@neau.edu.cn (Y.X.); wj@@neau.edu.cn (J.W.); zwq@neau.edu.cn (W.Z.); \\ wangqi@neau.edu.cn (Q.W.) \\ * Correspondence: tanghan@neau.edu.cn; Tel.: +86-451-5519-0950
}

check for

updates

Citation: Wang, J.; Xu, C.; Xu, Y.; Wang, J.; Zhou, W.; Wang, Q.; Tang, H. Resonance Analysis and Vibration Reduction Optimization of Agricultural Machinery Frame-Taking Vegetable Precision Seeder as an Example. Processes 2021, 9, 1979. https://doi.org/10.3390/ pr9111979

Academic Editor: Ján Pitel'

Received: 10 August 2021

Accepted: 4 November 2021

Published: 5 November 2021

Publisher's Note: MDPI stays neutral with regard to jurisdictional claims in published maps and institutional affiliations.

Copyright: (c) 2021 by the authors. Licensee MDPI, Basel, Switzerland. This article is an open access article distributed under the terms and conditions of the Creative Commons Attribution (CC BY) license (https:/ / creativecommons.org/licenses/by/ $4.0 /)$.

\begin{abstract}
In order to solve the problem of vigorous vibration of agricultural machinery frames, taking a vegetable precision seeder as an example, the concept of vibration reduction was proposed. The modal analysis of the frame was carried out, and the accuracy of the finite element model was verified by comparing the modal test of multipoint input and multipoint output (MIMO) and simulation results. Additionally, the main frequency of engine vibration was the main excitation source of frame resonance. According to the modal shapes, it was proposed to increase the fixed beam structure and to carry out simulation tests. The time-domain signal of the maximum deformation position in the first-order vibration mode was measured, and the vibration spectrum analysis maps before and after optimization were obtained by Fourier transform. A field experiment showed that the seeding quality of the whole machine was significantly improved after optimization. This study provides a reference for the analysis of vibration characteristics and the vibration reduction design of the agricultural machinery equipment.
\end{abstract}

Keywords: finite element method; modal test; field experiment; optimization; vibration characteristics

\section{Introduction}

Due to the large number of working parts and large vibration of agricultural machinery, it is easy to resonate with the frame, resulting in low reliability and fatigue damage. There are many kinds of agricultural machinery, but the overall configuration is composed of the engine, walking parts, working parts, and frame. In hilly and mountainous areas of China, the terrain is rugged and complex, and vegetables are planted by a vegetable precision seeder. The frame, as the backbone structure of the seeding device, plays the role of fixation and support [1-3]. At present, many power devices are installed on the frame to reduce labor intensity, but the vibration of the power device is transmitted to the frame causing a large disturbance of the population in the seeder equipped on the frame, reducing the success rate of series processes such as seed filling, seed protection, and seed feeding. Additionally, the qualified index is significantly reduced. At the same time, it is easy to cause fatigue damage in the weak links of the whole machine structure, affecting work reliability [4].

At present, there have been related studies on the problems of vigorous vibration and low reliability of various types of machinery during operation [5-7]. The reason for violent vibration is that the natural frequency of the structure is close to the excitation frequency and resonance occurs [8]; the natural frequency and vibration mode can be solved by simulation software. Winton et al. [9] conducted simulation research on the rigid body mode of heavy diesel engine block vibration and explored the relationship between engine mode order and vehicle simulation. Tong et al. [10] used ANSYS Workbench software to carry out a finite element modal analysis of the frame of a core stub collector, obtained 
the first 10 natural frequencies and vibration modes of the frame, and effectively analyzed the dynamic characteristics. Qiu et al. [11] extracted the first two natural frequencies and modal shapes of the spray bar, and combined them with ADAMS software to optimize the design of the spray bar. Although the simulation analysis is convenient and fast, the results tend to be idealized, which is different from the actual working state of the machine, so the structural vibration characteristics can be solved by the modal test. Li et al. [12] analyzed the coupling vibration of a belt drive system by the modal test method, which provided an important reference for the influence of running speed and initial tension on the natural frequency of agricultural machinery drive system. Ahmad et al. [13] collected the engine vibration time-domain signal by the modal test and analyzed the influence of different oil-gas mixing ratios on the vibration time-domain signal, which provided an effective way to characterize the engine vibration signal and reduce the engine vibration amplitude.

To explore the vibration characteristics of a mechanical structure is to optimize the design of the structure, so that the natural frequency of the structure is far away from the excitation frequency, effectively avoiding resonance and reducing the harm. Yao et al. [14] analyzed the field vibration characteristics of the frame by combining modal analysis with the vibration test and effectively improved the low-order natural frequency by improving the frame stiffness, which effectively avoided the vibration coupling between the frame and the engine. At present, optimization design methods are mainly divided into size optimization, shape optimization, and topology optimization [15]. Among them, topology optimization is widely used in aircraft wings and car bodies [16,17], and the current optimization is mainly size optimization. Jiang et al. [18] aimed to solve the problem of large amplitude caused by the excitation force generated by the movement of various parts of the rape mower frame, by installing an arch structure; the first-order natural frequency of the frame was effectively improved, avoiding the excitation frequency range of the excitation force of the elastic teeth of the conveyor belt and the cutter. Liu et al. [19] used finite element analysis software to simulate the mode and deformation of crankshaft under different counterweight conditions, and effectively reduced the vibration amplitude of the engine by installing different counterweights.

The above research mostly solved the natural frequency and modal shapes of the structure directly through simulation analysis, and less through the comparison and analysis of the natural frequency and mode of structure from the combination of simulation analysis and modal test. At the same time, the above optimization methods mainly change the overall structure form, which does not have universal applicability.

In order to solve the problem of violent vibration of the agricultural machinery frame, taking the frame of vegetable precision seeder as an example, this paper explored an effective method from the aspects of the vibration characteristic solution, resonance traceability, structure optimization, etc. In this paper, the natural frequency and modal shapes of the frame were solved by the combination of modal analysis and modal test, and the excitation frequency of the excitation source was calculated and tested. Based on the resonance theory, the main factors causing frame vibration were analyzed according to the frame modal shapes, the structure parameters, and installation dimensions of the fixed beam structure were simulated. This study provides a reference for vibration characteristic analysis and vibration reduction design of the same type of hand-held seeder and micro-tiller equipped with a power device. At the same time, the method of this study can be extended to a wide range of vibration reduction designs of agricultural machinery.

\section{Materials and Methods}

\subsection{Structure and Working Principle of the Vegetable Precision Seeder}

The vegetable precision seeder can complete a series of processes such as ditching, seeding, covering and pressing at one time, and is mainly composed of the driving wheel, opener, vegetable precision seed metering device, engine, soil covering device, suppressing wheel and frame, as shown in Figure 1. 


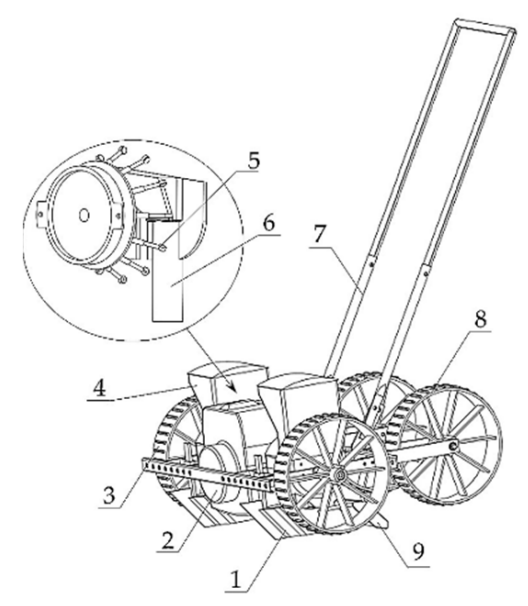

Figure 1. Structure diagram of the vegetable precision seeder: 1 . opener; 2 . engine; 3 . driving wheel; 4. vegetable precision metering device; 5 . seed scoop; 6 . seed guide tube; 7 . frame; 8 . suppressing wheel; 9. soil covering device.

The seeding device uses a gasoline engine as the matching power, and its power output shaft is transmitted to the driving wheel through the transmission system. The frame is mainly used as the bearing structure of each key component; the opener is arranged at the front end of the seed metering device, which breaks the hard soil, makes the soil loose and breathable, and provides a good growth environment for seeds before sowing.

The core components of the vegetable precision seed metering device are the seed scoop and the seed guide tube, and the seeds in the seed box were carried to the seed dropping area by the seed scoop and dropped into the seed guiding tube under the action of the scoop overturning and the seed gravity. The precision seed metering device can be adjusted transversely to meet the requirements of different vegetable seed row spacings. The soil covering device can cover the sown bare seeds with a thin layer of soil to avoid the influence of direct sunlight on the germination rate. The suppressing wheel is linearly arranged on the same side as the opener and the vegetable precision seed metering device, which can realize the pressing operation of vegetable seeds after sowing and covering the soil, ensure that the soil has good air permeability and water storage capacity, and improve the survival rate of seeds. In the field working, the gasoline engine transmitted the power to the driving wheel, and the opener arranged in front of the vegetable precision seed metering device opened a V-shaped deep ditch. The vegetable precision seed metering device sowed seeds into the seed ditch in an orderly manner, the soil covering device covered the seeds in the ditch, and finally the suppressing wheel pressed the covered seeds to complete the sowing work. Under the joint action of all series links, the combined sowing operations, such as ditching, sowing, covering, and suppressing, can be completed at one time, which effectively improves the stability and reliability of the overall operation effect. The main technical parameters are shown in Table 1.

Table 1. Technical parameters of the vegetable precision seeder.

\begin{tabular}{cc}
\hline Item & Parameter \\
Mass $/ \mathrm{kg}$ & 55 \\
Row spacing $/ \mathrm{mm}$ & $160-580$ (adjustable) \\
Plant spacing $/ \mathrm{mm}$ & $50-300$ (adjustable) \\
Seeding depth $/ \mathrm{mm}$ & $50-150$ (adjustable) \\
Overall dimensions $/ \mathrm{mm}$ & $824 \times 672 \times 1050$ \\
Working width $/ \mathrm{mm}$ & $492 \sim 912$ \\
\hline
\end{tabular}




\subsection{Finite Element Modal Analysis of Frame}

The main external excitation sources of the vegetable precision seeder were the gasoline engine and ground, etc. In order to accurately explore the main factors affecting the vibration of the frame and to avoid the problems of poor operation quality and low reliability caused by the coupling of excitation source frequency and the natural frequency of the frame, the modal simulation analysis of the frame was carried out, and its modal characteristics were solved, which provided a theoretical basis and data reference for optimizing the structural parameters of the frame to avoid resonance.

The research object of this paper is the vegetable precision seeder frame. The whole structure is made up of the armrest bracket, adjusting bracket, seed metering device fixed bracket, roller bracket, and other key components rigidly welded with the fixed beam. The armrest bracket and the adjusting bracket are nested within each other and are fixed and connected by bolts, which is convenient for disassembly and transportation. The main supports are a hollow round pipe and solid square steel structure formed by Q235 structural steel. The model of the frame of vegetable precision seeder established by three-dimensional modeling software CATIA is shown in Figure 2.

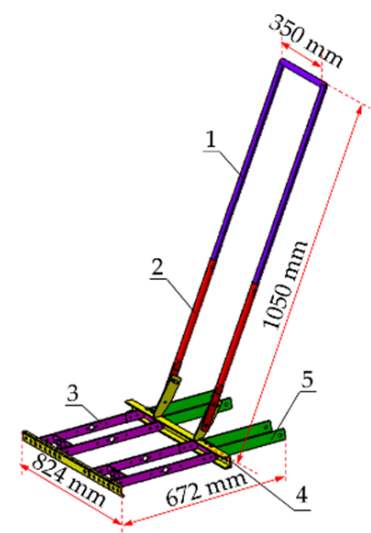

Figure 2. The model of frame: 1 . armrest bracket; 2. adjusting bracket; 3. fixing bracket of seed metering device; 4 . cross beam; 5 . suppressing wheel bracket.

Since the seeding device frame is welded from the structural steel bracket and needs to fix a large number of key components, there are many solder joints and installation holes on it. In order to accurately establish the finite element model of the frame and obtain high-quality meshes, it is necessary to simplify the frame [20]. Therefore, the installation holes smaller than the mesh size and the change in material properties caused by solder joints were ignored, while the local characteristics, such as bolts, chamfers, and rounded corners, were ignored to save simulation time and simplify the frame into a rigid connection model [21-23]. The frame material was set as Q235 structural steel, and its elastic modulus was $210 \mathrm{GPa}$, Poisson's ratio was 0.3 , density was $7850 \mathrm{~kg} / \mathrm{m}^{3}$, and yield strength was $235 \mathrm{MPa}$. The three-dimensional solid model of the frame was saved in igs format and imported into the finite element analysis software ANSYS Workbench. The mesh was divided by the ANSYS Mesh module, and the mesh quality was controlled by setting size. According to the size of the solid model, the element size was set to $5 \mathrm{~mm}$. After surface meshing of the face, the total number of elements was 21,735, and the total number of nodes was 58,371 . The finite element model of the frame obtained by grid division is shown in Figure 3.

As the support foundation of the seeding device, the frame plays a vital role in the stability and reliability of the overall structure. When the frame's natural frequency is coupled with the external excitation frequency, resonance will cause noise and damage. Modal analysis can determine the vibration characteristics of the frame, and obtain the natural frequencies and modal shapes of each order [24]. Therefore, the free modal analysis of the frame was carried out. 


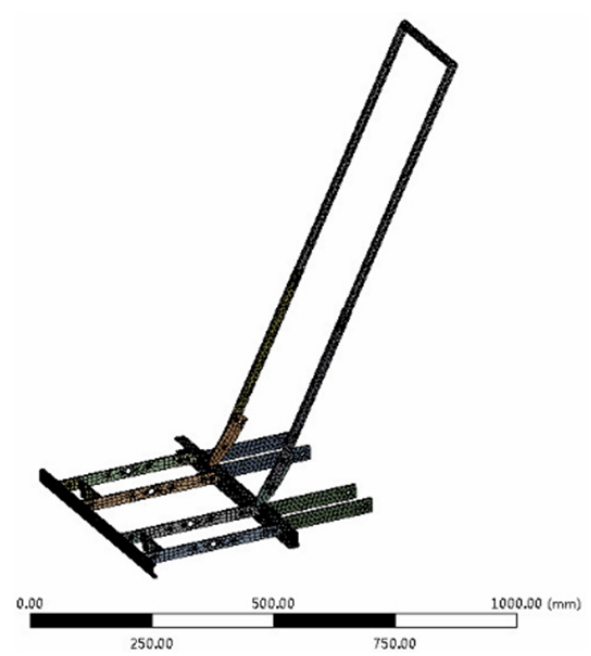

Figure 3. Grid division of frame model.

As the low-order modal characteristics are easy to excite and have a great impact on the structural vibration, the rigid-body modes with the first six order frequencies of zero will be solved in the free state, that is, the structural modal characteristics in the three-way translational and three-way rotational states [25-27]. The non-zero first six order modal shapes and natural frequencies were obtained using the finite element analysis software ANSYS Workbench, as shown in Figure 4.

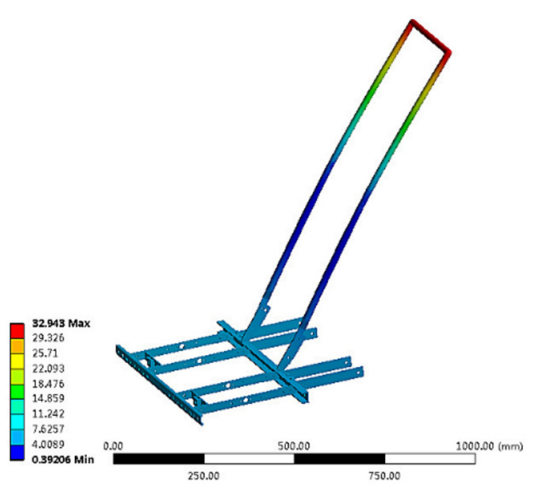

(a)

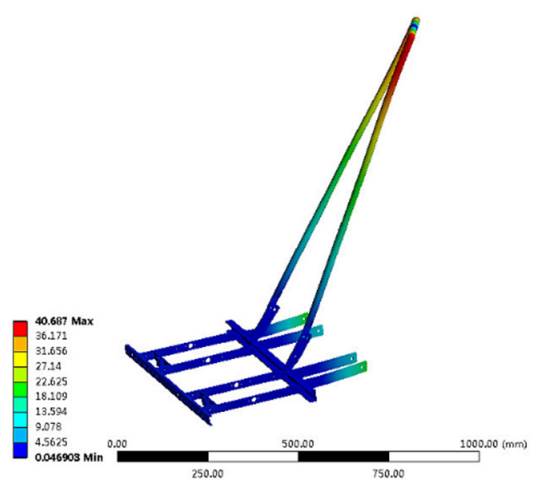

(d)

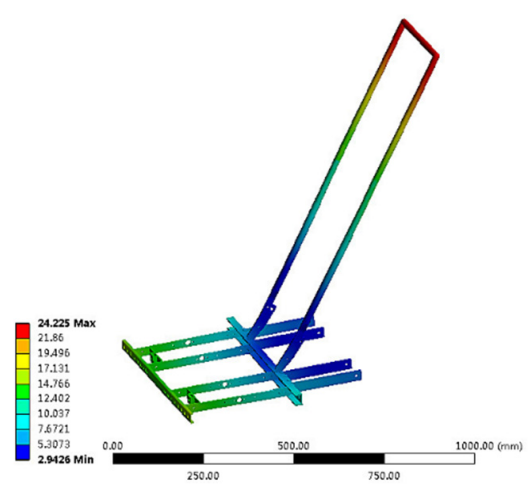

(b)

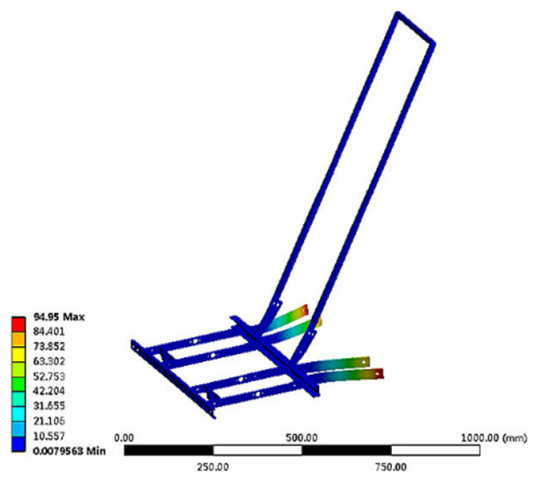

(e)

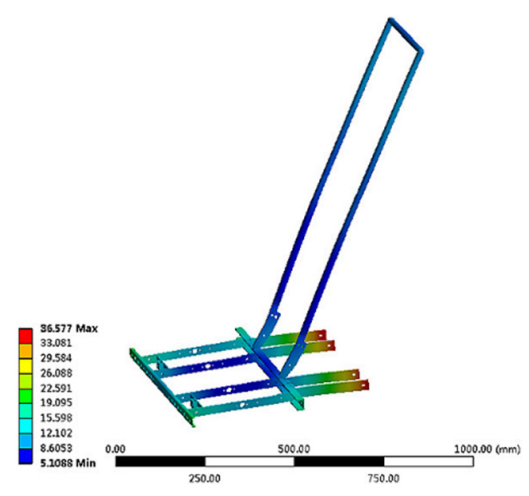

(c)

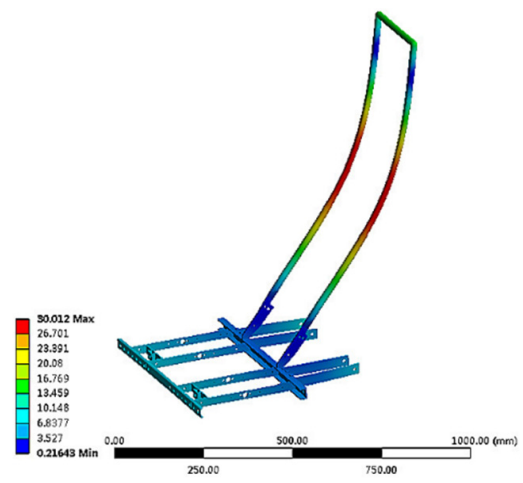

(f)

Figure 4. The modal shapes and corresponding frequencies of frame finite element modal analysis: (a) is the 1st order mode shape and its frequency is $11.43 \mathrm{~Hz}$; (b) is the 2nd order mode shape and its frequency is $17.62 \mathrm{~Hz}$; (c) is the 3rd order mode shape and its frequency is $28.25 \mathrm{~Hz}$; (d) is the 4th order mode shape and its frequency is $42.30 \mathrm{~Hz}$; (e) is the 5th order mode shape and its frequency is $62.17 \mathrm{~Hz}$; (f) is the 6th order mode shape and its frequency is $76.78 \mathrm{~Hz}$. 
It can be seen from the first six order modal shapes of the frame that when resonance occurs, the armrest bracket and the suppressing wheel bracket were the main deformation parts, among which the main deformation forms of the armrest bracket were bending and torsion, mainly due to its large span and lack of support. The main deformation form of suppressing wheel bracket was bending.

\subsection{Modal Test of Frame}

In the modal test, a force hammer was used to excite the frame, and an accelerometer was used to select the multipoint pick-up response to identify the modal parameters of the system, which provided a basis for the analysis of the vibration characteristics of the structural system and the optimization design of the structural dynamic characteristics. The accuracy of the finite element modal analysis results can be effectively verified by the modal test.

The modal test equipment mainly consisted of an INV3018C 8-channel 24-bit highprecision data acquisition instrument (Beijing Dongfang Institute, Beijing, China), LC-2D force hammer (Beijing Dongfang Institute, Beijing, China), AY100I piezoelectric acceleration sensor (Beijing Dongfang Institute, Beijing, China), DASP-10 modal analysis system (Beijing Dongfang Institute, Beijing, China), computer, etc. Its structural parameters are shown in Table 2.

Table 2. Test instruments and technical parameters.

\begin{tabular}{|c|c|c|c|}
\hline Order & Instrument Name & Parameter & Illustration \\
\hline 1 & Computer & / & \\
\hline 2 & $\begin{array}{l}\text { INV3018C 8-channel 24-bit } \\
\text { high-precision data } \\
\text { acquisition instrument }\end{array}$ & $\begin{array}{c}\text { Parallel channel: } 8 \\
\text { Maximum sampling frequency: } 102.4 \mathrm{kHz} \\
\text { A/D resolution: } 24 \text { bits }\end{array}$ & \\
\hline 3 & LC-2D force hammer & $\begin{array}{c}\text { Measuring range: } 0-2 \mathrm{kHz} \\
\text { Charge reference sensitivity: } 4 \mathrm{pC} / \mathrm{N} \\
\text { Linearity: }<1 \%\end{array}$ & \\
\hline 4 & AY100I piezoelectric acceleration sensor & $\begin{array}{c}\text { Sensitivity: } 100 \mathrm{mV} / \mathrm{g} \\
\text { Maximum frequency: } 10,000 \mathrm{~Hz} \\
\text { Resolution: } 0.0002\end{array}$ & \\
\hline \multirow{2}{*}{5} & DASP-10 modal analysis system & 1 & Fi: \\
\hline & & & 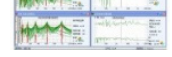 \\
\hline
\end{tabular}

The test modal analysis was to decompose a complex multi-degree-of-freedom system into several subsystems. First, several low-order modes of each subsystem were obtained, and then each subsystem was assembled into a system of differential equations of overall motion according to the displacement coordination relationship or force balance relationship of adjacent systems, and the comprehensive characteristic problem of reduced degrees of freedom was derived [28]. Through the vibration test of the actual structure, the excitation force was applied to the machine and the response was measured; the modal parameters of the vibration system were identified; the transfer functions of each subsystem were solved, and the natural frequencies and the modal shapes were finally calculated. The test schematic diagram is shown in Figure 5. 


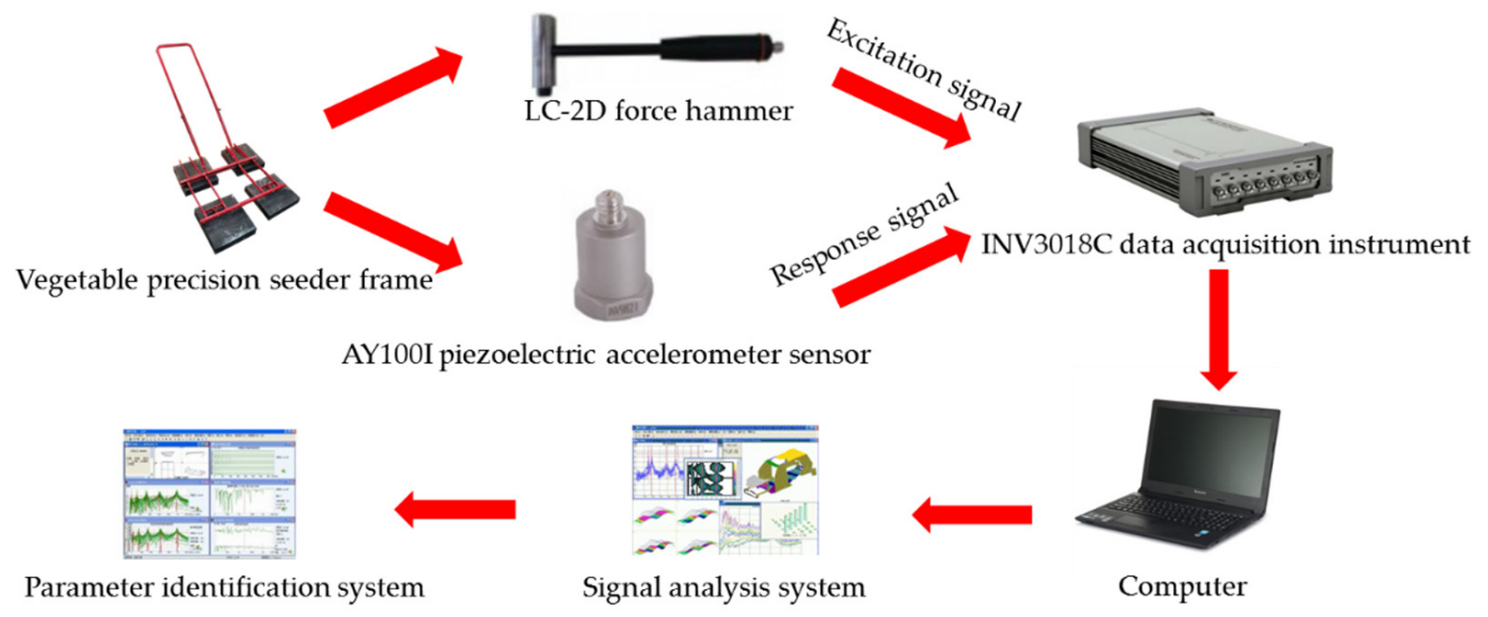

Figure 5. Test schematic diagram.

For a linear system with multiple degrees of freedom, it can be expressed by a system of second-order differential Equation [29]:

$$
[M]\{\ddot{x}\}+[C]\{\dot{x}\}+[K]\{x\}=\{f\}
$$

where $[M],[C]$, and $[K]$ are the mass, damping, and stiffness matrices, respectively; $\{f\}$ is the excitation force vector; $\{x\}$ is the displacement; $\{\dot{x}\}$ is the velocity; and $\{\ddot{x}\}$ is the acceleration. The Formula (1) is obtained by Laplace transformation:

$$
[Z(s)]\{X(s)\}=\{F(s)\}
$$

where $\{X(s)\}$ is the system response. The Formula (3) is the impedance matrix.

$$
\begin{gathered}
{[Z(s)]=s^{2}[M]+s[C]+[K]} \\
H(s)=[Z(s)]^{-1}
\end{gathered}
$$

The inverse matrix of the system impedance matrix $Z(s)$ is the admittance matrix, which is the transfer function matrix of the system.

For the structure with proportional viscous damping excited at the point $p$, the real mode expansion of the transfer function of the response at point $l$ is:

$$
H_{l p}(s)=\frac{X_{l}}{F_{p}}=\sum_{l=1}^{n} \frac{\varphi_{l i} \varphi_{p i}}{m_{i} s^{2}+c_{i} s+k_{i}}
$$

where $\varphi_{l i}, \varphi_{p i}$ are the $l$ and $p$ elements of the $i$ principal mode vector, also known as the main mode vectors of points $l$ and $p$.

For structural damping, there is:

$$
H_{l p}(s)=\sum_{i=1}^{n} \frac{\varphi_{l i} \varphi_{p i}}{m_{i} s^{2}+k_{i}+j g k_{i}}
$$

where $g$ is the damping coefficient of the structure.

For complex modes, the transfer function formula is as follows:

$$
[H(s)]=\frac{\operatorname{adj}[Z(s)]}{\operatorname{det}[Z(s)]}
$$


Each element of $[H(s)]$ can be written as follows:

$$
H_{l p}=\frac{a_{0}+a_{1} s+a_{2} s^{2}+\ldots \ldots+a_{2 n-2} s^{2 n-2}}{b_{0}+b_{1} s+b_{2} s^{2}+\ldots \ldots+b_{2 n-2} s^{2 n-2}}
$$

where $a_{i}(i=0,1,2,2 n-2)$ and $b_{i}(i=0,1,2,2 n)$ are real constants.

According to the theory of complex function, it can also be written in the form of residue:

$$
H_{l p}(s)=\sum_{i=1}^{n}\left[\frac{A_{l p i}}{s-s_{i}}+\frac{A_{l p i}^{*}}{s-s_{i}^{*}}\right]
$$

where $A_{l p i}^{*}$ is the residue of the complex function; $H_{l p}(s)$ at the extreme point; $s_{i}$ is the modal constant; $s_{i}$ and $s_{i}^{*}$ are the poles of the transfer function, the $i$-order natural frequency.

When the transfer function of the system is known, the natural frequency, damping ratio, modal shape, modal mass, and other modal parameters can be calculated.

To ensure that the rigid body mode was less than $1 / 3$ of the first-order elastomer mode, the frame was placed on the rubber block before the test [30]. In order not to introduce additional mass and to decompose the mode easily, the multiple input multiple output (MIMO) method was adopted in the test [31]. A force hammer was used to strike all measuring points of the frame to exert excitation. The force sensor on it and the acceleration sensor arranged at multiple response points simultaneously collected excitation and response signals and transmitted them to the data acquisition instrument. The system matrix of minimum order was obtained by FRF calculation, pulse response function solution, ERA mode fitting, and other steps through the DASP-10 modal analysis system to identify the natural frequencies and modal shapes. The frame modal test is shown in Figure 6.

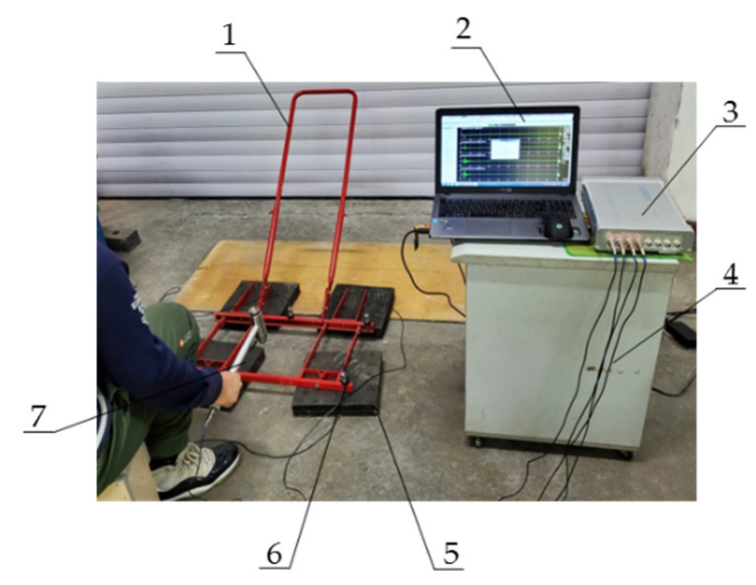

Figure 6. Modal test: 1 . frame; 2. computer; 3. data acquisition instrument; 4 . signal transmission line; 5 . rubber block; 6 . acceleration sensor; 7 . force hammer.

Among them, the layout of measuring points not only reflects the overall shape of the mechanism, but also the action point of external force and the structural intersection point. At the same time, it is necessary to ensure that all measuring points are excited by the force hammer and have a high signal-to-noise ratio [32]. Finally, a hammer model with 46 measuring points was established, as shown in Figure 7. The arrangement of response points requires that the nodes can be avoided and the response signals can be easily received. Acceleration sensors were arranged at 7, 25 and 30 measuring points of the hammer model. 


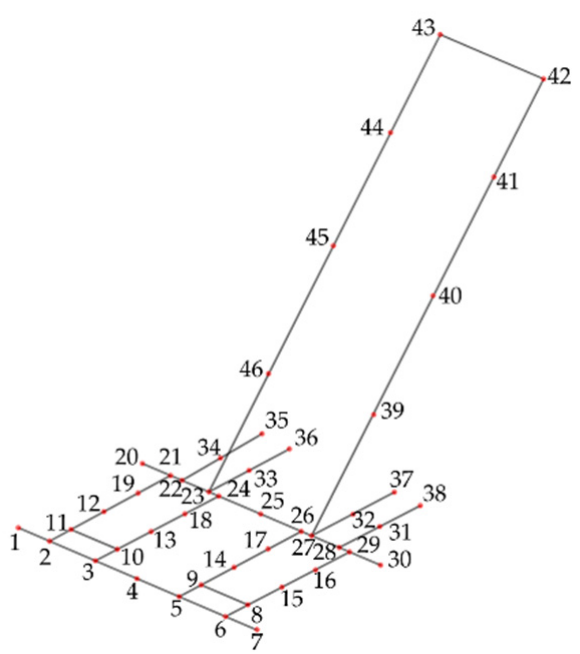

Figure 7. Hammer model of measuring point of the frame.

\subsection{Excitation Source Analysis}

By analyzing the structure composition and actual working conditions of the vegetable precision seeder, the excitation sources causing the vibration of the frame are mainly the ground and the engine, in which the ground excitation frequency is generally $0-3 \mathrm{~Hz}$ [33]. The excitation source generated by the engine is mainly due to the vibration caused by the periodic change in the pulse torque output of the crankshaft caused by the mixture combustion, and the calculation formula is as follows:

$$
f=\frac{2 n i_{a}}{60 c}
$$

where $f$ is the excitation frequency, Hz. $n$ is the engine speed, r/min. $i_{a}$ is the number of engine cylinders, and $c$ is the number of engine strokes.

The device is equipped with a Mitsubishi TU-1.7HP gasoline engine (Mitsubishi Corporation, Tokyo, Japan), which is of a single cylinder, two stroke air-cooled type. When the speed is $700 \mathrm{r} / \mathrm{min}$ in normal working, the excitation frequency is $11.67 \mathrm{~Hz}$.

The firing order of the two-stroke engine is mainly the first order. In order to verify the accuracy of calculating the excitation frequency during normal working, the engine vibration condition was tested in the room. The engine speed was maintained at $700 \mathrm{r} / \mathrm{min}$. The spectral characteristics of the engine were obtained by Fourier transform, as shown in Figure 8 .

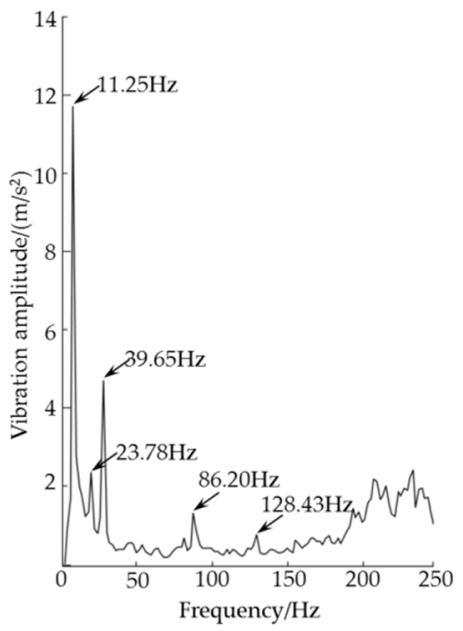

Figure 8. Engine frequency spectrum characteristic diagram. 


\subsection{Optimization and Analysis of Frame}

According to the first-order vibration characteristics and modal shapes of the frame, we proposed to increase the first natural frequency by adding a fixed beam structure on the armrest bracket to avoid the excitation range of the engine and to effectively avoid resonance. There are many ways to increase the fixed beam. Its purpose is to improve the range of the first-order natural frequency and reduce the vibration amplitude of the frame. For example, one or more transverse or longitudinal fixed beams or one or more diagonal fixed beams are added to the handrail support. However, multiple fixed beams increase the counterweight of the whole machine and complicate the structure at the same time. Taking a single fixed beam as an example, this study analyzed the changes of its size and position on the vibration characteristics of the frame structure. Fixed beams were installed between the armrest bracket and the adjusting bracket. By exploring the influence of installation position (distance from the top of the armrest bracket) and diameter on the natural frequency, the optimal combination of structural parameters and installation position of fixed beams was determined to provide a reasonable basis for improving the first-order natural frequency and reducing the resonance effect.

The length of the fixed beam depended on the span of the armrest bracket and was constant at $350 \mathrm{~mm}$. The material was Q235 structural steel, which was the same as the frame. Based on the overall length and diameter of the armrest bracket and the adjusting bracket, the change interval of the installation position was set at $200-1000 \mathrm{~mm}$, and the change interval of the diameter was $4-8 \mathrm{~mm}$. The modal analysis of different structures of the frame was carried out by ANSYS Workbench 18.0 to explore the influence of installation position and diameter on the natural frequency, as shown in Figure 9.

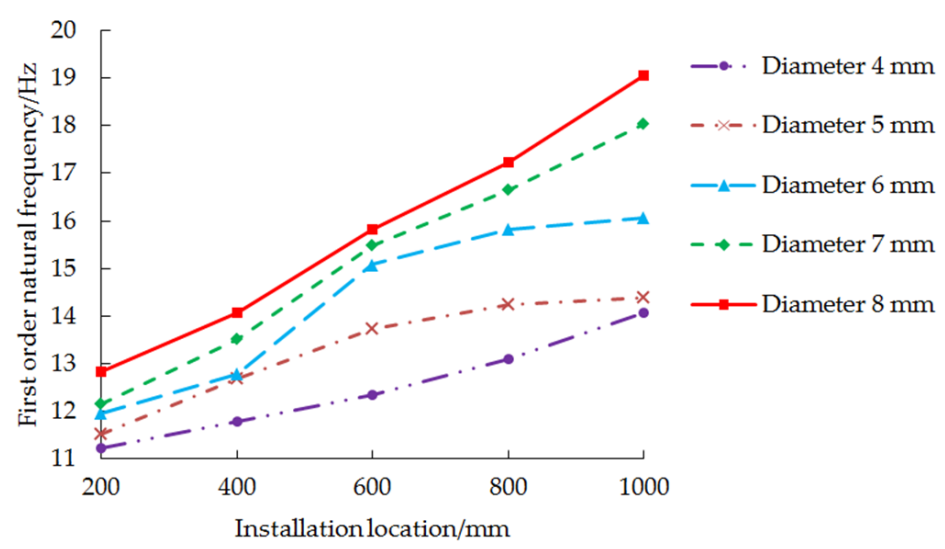

Figure 9. Influence of installation position and diameter on natural frequency of frame.

According to the resonance theory, resonance occurs when the natural frequency of the structure has the following relationship with the external excitation frequency [34], that is:

$$
0.8 f_{c} \leq f \leq 1.2 f_{c}
$$

where $f_{c}$ is the natural frequency of the structure, and Hz. $f$ is the external excitation frequency, $\mathrm{Hz}$.

Since the excitation frequency of the gasoline engine is $11.25 \mathrm{~Hz}$, the natural frequency range of the frame causing resonance is within $9.38 \mathrm{~Hz} \leq f_{c} \leq 14.06 \mathrm{~Hz}$. To improve the natural frequency of the frame to avoid resonance, the requirement of $f_{c}>14.06 \mathrm{~Hz}$ is met.

From the analysis of Figure 8, it can be seen that the first-order natural frequency of the fixed beam with the same diameter increases with the increase in the installation position, and the first-order natural frequency of the same installation position increases with the increase in the fixed beam diameter. 
When the diameter of the fixed beam was $4 \mathrm{~mm}$ and $5 \mathrm{~mm}$, respectively, the maximum natural frequencies of the first order of the frame were installed at $1000 \mathrm{~mm}$ away from the top of the armrest bracket, and their maximum values were $14.08 \mathrm{~Hz}$ and $14.39 \mathrm{~Hz}$, respectively, which were still in the frequency range where the resonance of the frame occurs. The combinations of diameter and installation position of the fixed beam that can avoid resonance were $6 \mathrm{~mm}$ and $600 \mathrm{~mm}, 6 \mathrm{~mm}$ and $800 \mathrm{~mm}, 6 \mathrm{~mm}$ and $1000 \mathrm{~mm}$, $7 \mathrm{~mm}$ and $600 \mathrm{~mm}, 7 \mathrm{~mm}$ and $800 \mathrm{~mm}, 7 \mathrm{~mm}$ and $1000 \mathrm{~mm}, 8 \mathrm{~mm}$ and $600 \mathrm{~mm}, 8 \mathrm{~mm}$ and $800 \mathrm{~mm}$, and $8 \mathrm{~mm}$ and $1000 \mathrm{~mm}$. Through modal analysis, the first-order natural frequencies were $15.04 \mathrm{~Hz}, 15.83 \mathrm{~Hz}, 16.07 \mathrm{~Hz}, 15.49 \mathrm{~Hz}, 16.65 \mathrm{~Hz}, 18.02 \mathrm{~Hz}, 15.83 \mathrm{~Hz}$, $17.23 \mathrm{~Hz}$, and $19.06 \mathrm{~Hz}$, respectively. In order to reduce the material application and ensure the lightweight design of the optimized frame structure, a fixed beam diameter of $6 \mathrm{~mm}$ was selected.

At the same time, according to the first-order modal shapes and the mass distribution of the whole structure when resonance occurs, the fixed beam should be installed in the middle position of the span of the armrest bracket as far as possible, and finally, the diameter of the fixed beam and the installation position should be combined as $6 \mathrm{~mm}$ and $600 \mathrm{~mm}$. The new frame structure after final optimization is shown in Figure 10.

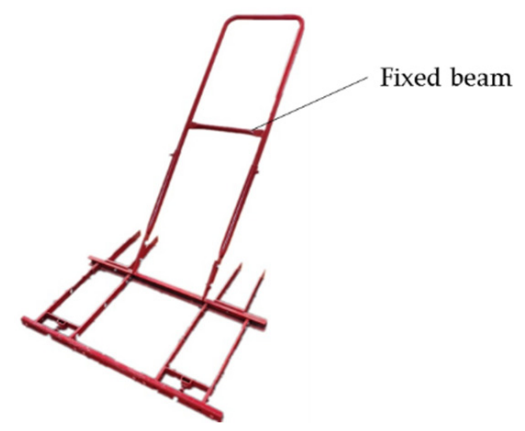

Figure 10. Optimized frame structure.

\subsection{Field Experiment}

Vibrations will be transmitted to the seeder through the frame structure, which seriously affects the uniformity and stability of seeding. In order to further explore the effect of the optimized frame on seeding, a seeding performance comparison test, before and after frame optimization, was carried out. The experiment was carried out in the experimental base of the Engineering College of Northeast Agricultural University in June 2021, as shown in Figure 11.

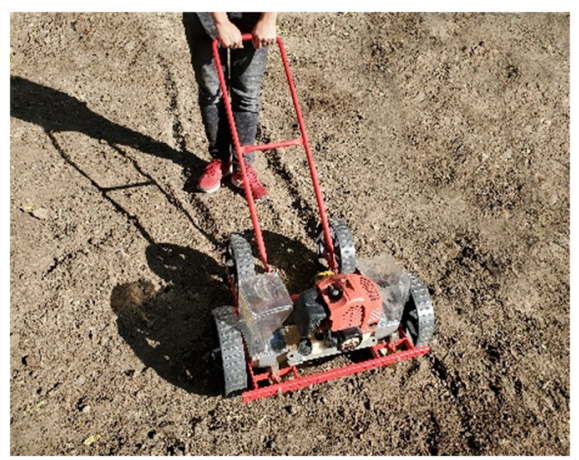

(a)

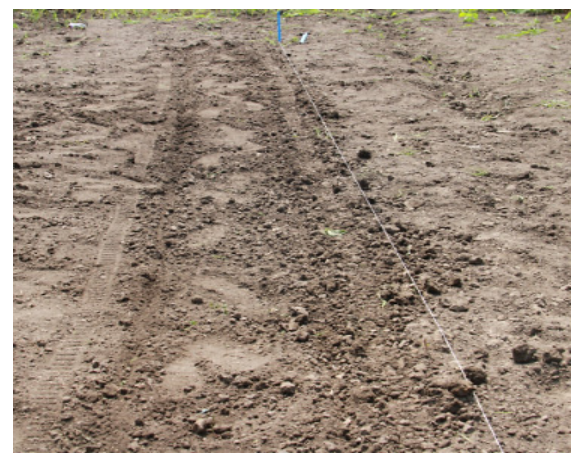

(b)

Figure 11. Field experiment: (a) experimental site; (b) sowing effect. 
The seed of Boshou No.1 Chinese cabbage was selected as the test variety, and its basic physical characteristics were as follows (mean value) triaxial size was $1.73 \mathrm{~mm}, 1.64 \mathrm{~mm}$, and $1.57 \mathrm{~mm}$; 1000-grain weight was $2.95 \mathrm{~g}$, density was $0.673 \mathrm{~g} / \mathrm{cm}^{3}$, and water content was $13.2 \%$. In order to reach the state of waiting for sowing, rotary tillage was carried out before the experiment, the soil moisture content after the tillage was $15.26 \%$, and the soil firmness was $1.15 \mathrm{MPa}$, which met the vegetable sowing agronomic requirements. According to the agronomic requirements of the National Standard of P.R.C. (GB/T 69732005 Testing Methods of Single Seed Drills (Precision Drills)), the grain distance qualified index, multiples index and miss index were selected as the sowing performance indexes, and the coefficient of variation was the sowing uniformity index. The related calculation equations are as follows:

$$
\begin{gathered}
\left\{\begin{array}{c}
Q=\frac{n_{0}}{N} \times 100 \% \\
P=\frac{n_{1}}{N} \times 100 \% \\
M=\frac{n_{2}}{N} \times 100 \%
\end{array}\right. \\
C=\sqrt{\frac{\sum(x-\bar{x})}{\left(n^{\prime}-1\right) \bar{x}^{2}}} \times 100 \%
\end{gathered}
$$

where $Q$ is the qualified index, \%; $P$ is the multiples index, $\% ; M$ is the leak index, \%; $C$ is the coefficient of variation, $\% ; n_{0}$ is the number of holes in one seed; $n_{1}$ is the number of holes with more than one seeds; $n_{2}$ is the number of holes without seeds; $N$ is the total number of holes in the range of sowing, $n^{\prime}$ is the total amount of sample seed-spacing; $x$ is the theoretical seed-spacing of seeding, $\mathrm{mm} ; \bar{x}$ is the average distance between sample points, $\mathrm{mm}$.

During the test, the engine speed was ensured to be $700 \mathrm{r} / \mathrm{min}$, the theoretical particle distance was $150 \mathrm{~mm}$, the length of the test area was $100 \mathrm{~m}$, and the seeds in the seed box were not less than 1500. The test was repeated three times, and the results were taken as the average.

\section{Results and Discussion}

\subsection{The Results of Modal Test and Resonance Analysis}

The natural frequencies and modal shapes of the frame in the test were obtained by the time domain signal acquisition of excitation and response, calculation of the FRF frequency response function, solution of the pulse response function, and ERA modal fitting, as shown in Figure 12.

To verify the modal correlation of the test modes, the modal assurance criterion $(M A C)$ was used to evaluate the modal correlation matrix, and its verification is shown in Figure 13. The $M A C$ was the correlation coefficient between two vectors. The $M A C$ value of two vectors of the same physical model was close to 1 , while the $M A C$ value between two vectors of different modes was smaller, indicating that the two modal vectors had approximately the same modality. The basic idea was to assume that the mass of the structure was approximately uniformly distributed, then the modal shapes of the structure have unweighted orthogonality. The modal correlation coefficient is defined as follows [35]:

$$
M A C_{i j}=\frac{\left|\left(\Phi_{i}^{e T} \Phi_{j}^{a}\right)\right|^{2}}{\left(\Phi_{i}^{e T} \Phi_{i}^{e}\right)\left(\Phi_{j}^{a T} \Phi_{j}^{a}\right)}=\left\{\begin{array}{l}
0(i \neq j) \\
1(i=j)
\end{array}\right.
$$

where $M A C_{i j}$ is the correlation coefficient between the $i$ order mode shape and the $j$ order mode shape of the test. $\Phi_{i}^{e}$ represents the $i$ order mode shape. $\Phi_{j}^{a}$ represents the $j$ order mode shape. $T$ represents the conjugate transposition. 


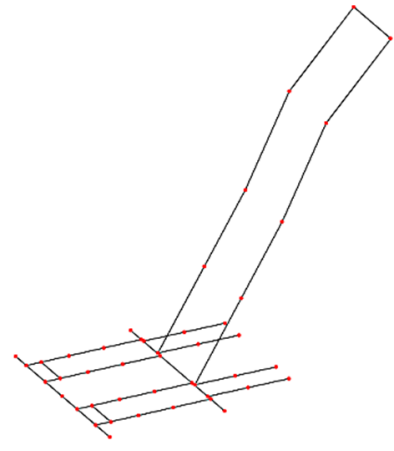

(a)

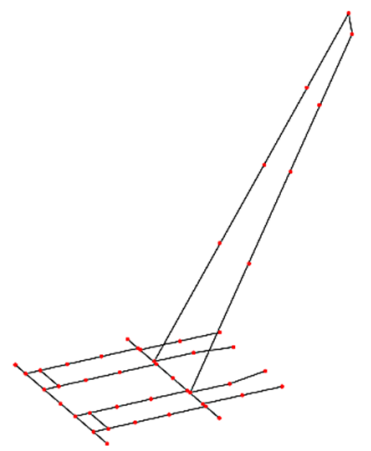

(d)

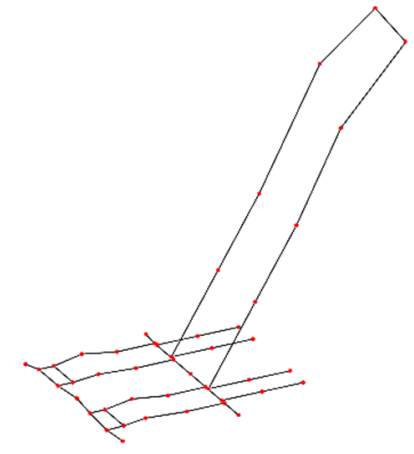

(b)

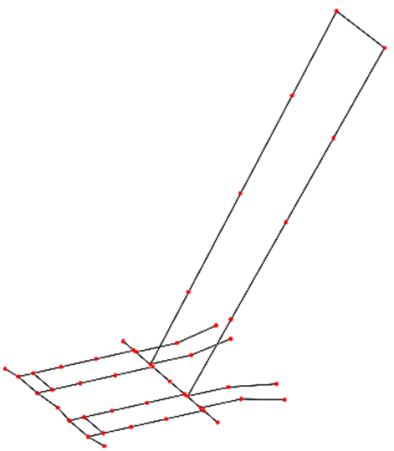

(e)

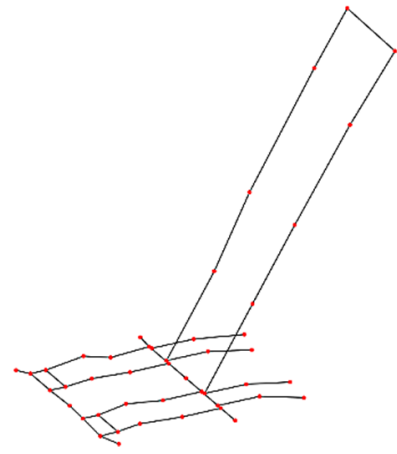

(c)

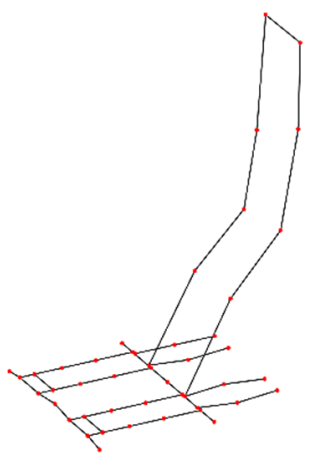

(f)

Figure 12. The modal shapes and corresponding frequencies of modal test: (a) is the 1st order mode shape and its frequency is $11.08 \mathrm{~Hz}$; (b) is the 2nd order mode shape and its frequency is $16.97 \mathrm{~Hz}$; (c) is the 3rd order mode shape and its frequency is $29.13 \mathrm{~Hz}$; (d) is the 4th order mode shape and its frequency is $42.25 \mathrm{~Hz}$; (e) is the 5th order mode shape and its frequency is $60.80 \mathrm{~Hz}$; (f) is the 6th order mode shape and its frequency is $77.44 \mathrm{~Hz}$.

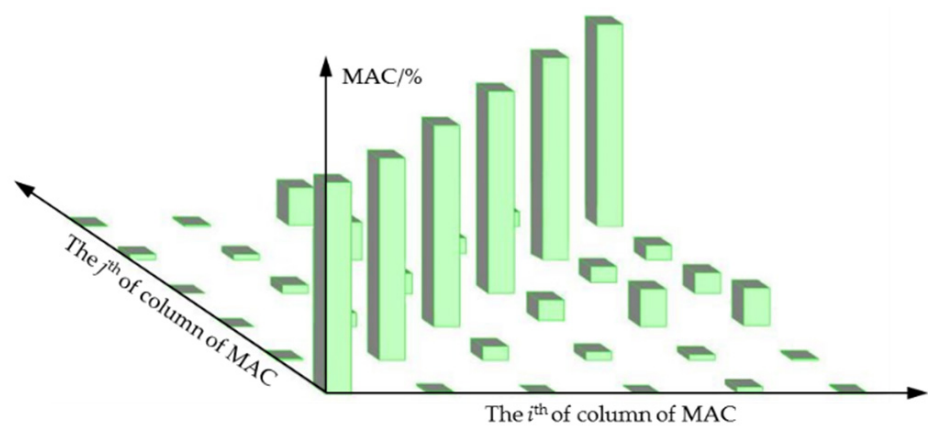

Figure 13. Modal shape correlation matrix of frame modal test: MAC stands for modal assurance criterion.

It can be seen from Figure 13 that the correlation coefficient between the diagonal element and the modality itself is constant at 1 , and the peak values of the non-diagonal element are less than the discriminant correlation threshold of 0.3 , which indicates that the orthogonality between the two vectors is good, and the first six order modes of the frame assembly are independent modes that are not mutually coherent. The test results had good coherence, and the reliability of the modal test parameters results was high.

The results of finite element modal analysis and modal test were compared, as shown in Table 3. Based on the natural frequency obtained by the modal test, the results of finite element modal analysis and modal test were compared, and the error calculation method is Equation (15).

$$
e=\frac{\left|F_{1}-F_{2}\right|}{F_{2}} \times 100 \%
$$

where $e$ is the error, $\% ; F_{1}$ is the calculated frequency, Hz; $F_{2}$ is the Test frequency, Hz. 
Table 3. Comparison between finite element modal analysis and modal test.

\begin{tabular}{|c|c|c|c|c|c|}
\hline \multirow[b]{2}{*}{ Order } & \multicolumn{2}{|c|}{ Finite Element Modal Analysis } & \multicolumn{2}{|c|}{ Modal Test } & \multirow[t]{2}{*}{ Error/\% } \\
\hline & $\begin{array}{c}\text { Calculated } \\
\text { Frequency/Hz }\end{array}$ & Modal Shape & $\begin{array}{c}\text { Test } \\
\text { Frequency/Hz }\end{array}$ & Modal Shape & \\
\hline 1 & 11.43 & Handrail bracket bending & 11.08 & Consistent & 3.15 \\
\hline 2 & 17.62 & $\begin{array}{l}\text { Handrail bracket } \\
\text { bendingBeam bending }\end{array}$ & 16.97 & Consistent & 3.83 \\
\hline 3 & 28.25 & $\begin{array}{l}\text { Bending of the beam, } \\
\text { deformation of the support } \\
\text { of the crushing wheel }\end{array}$ & 29.13 & Consistent & 3.02 \\
\hline 4 & 42.30 & $\begin{array}{l}\text { Torsion of armrest bracket } \\
\text { Bending of the beam and }\end{array}$ & 42.25 & Consistent & 0.12 \\
\hline 5 & 62.17 & $\begin{array}{l}\text { deformation of the support } \\
\text { of the crushing wheel }\end{array}$ & 60.80 & Consistent & 2.25 \\
\hline 6 & 76.78 & Handrail bracket bent & 77.44 & Consistent & 0.85 \\
\hline
\end{tabular}

Table 3 shows that the mode shapes of finite element modal analysis are basically consistent with the modal test, and there is a certain error between frequencies; the maximum error value is $3.83 \%$. The errors may be caused by the following: (1) Some mounting holes and small load-transfer structures were neglected in the establishment of the frame finite element model. (2) The meshing quality of the finite element modal analysis affected the natural frequency calculation results, and the noise interference during the signal acquisition in the modal test affected the measurement accuracy. (3) In the modal test, the frame was padded with a rubber block to ensure that the rigid body mode was less than $1 / 3$ of the first elastic body mode, which was approximately in a free state, while the finite element modal analysis software can simulate the absolute free state. Within the allowable range of error, the frame finite element model was accurate and reasonable, which laid the foundation for the optimization analysis and design.

From Figure 8, it can be seen that the main frequency of engine vibration was $11.25 \mathrm{~Hz}$, which was close to the calculated excitation frequency, indicating that the first-order ignition order of the two-stroke engine is the main frequency of vibration in normal working. Comprehensive analysis showed that the first-order natural frequency of the frame fell within the excitation frequency range of the engine and was prone to resonance; that is, the engine was the main factor affecting the vibration of the frame.

\subsection{The Results of Frequency Comparison}

In order to describe whether the multi-order natural frequencies of the optimized frame have frequency exchange, the modal analysis for optimized frame structure was carried out, and the data were sorted into Excel 2010 to compare the natural frequencies of the frame before and after optimization, as shown in Figure 14.

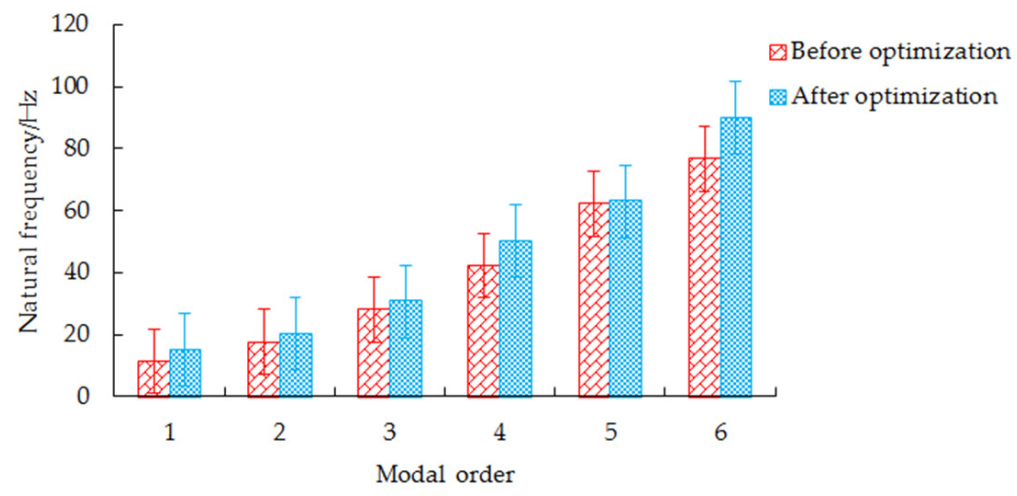

Figure 14. Frequency comparison of each order before and after optimization. 
From the analysis of Figure 14, it can be seen that the six order natural frequencies of the optimized frame all show different degrees of increase, and no frequency exchange phenomenon occurs, which indicates that the natural frequencies can be effectively improved by increasing the fixed beam structure, and the resonance can be avoided.

\subsection{Analysis of Vibration Characteristics of Optimized Frame}

In order to verify the vibration characteristics of the optimized frame, the acceleration time-domain signals of $X, Y$, and $Z$ ( $X$-axis in the forward direction of the seeding device, $Y$-axis in the horizontal direction perpendicular to $X$-axis and $Z$-axis in the vertical direction) of the maximum deformation position (measuring point 44) in the first-order modal shapes of the gasoline engine at $700 \mathrm{r} / \mathrm{min}$ were collected. The vibration spectrum analysis maps were obtained by self-spectrum analysis based on Fourier transform. At the same time, in order to test the effect of the improved frame on the seeding effect, a field seeding performance comparison test, before and after optimization, was carried out.

In order to validate the optimized vibration characteristics of the frame effectively and avoid the interference of human factors, the acceleration test of the frame measuring points was carried out in the room as the research objects. The test equipment included INV9832-50 acceleration sensor (Beijing Dongfang Institute, Beijing, China), a signal acquisition analyzer, and a computer. Before vibration signal acquisition, the sampling mode was set as continuous sampling, with a sampling frequency of $2560 \mathrm{~Hz}$, time-domain number of points of 44,096, and frequency domain line number of 1600 . The acquisition was performed three times, each time for $20 \mathrm{~s}$, and the acceleration data number was recorded. The driving wheel was suspended to put the whole machine into a static state, and the vibration time domain signal of the frame was collected under the condition of $700 \mathrm{r} / \mathrm{min}$ of the gasoline engine, as shown in Figure 15.

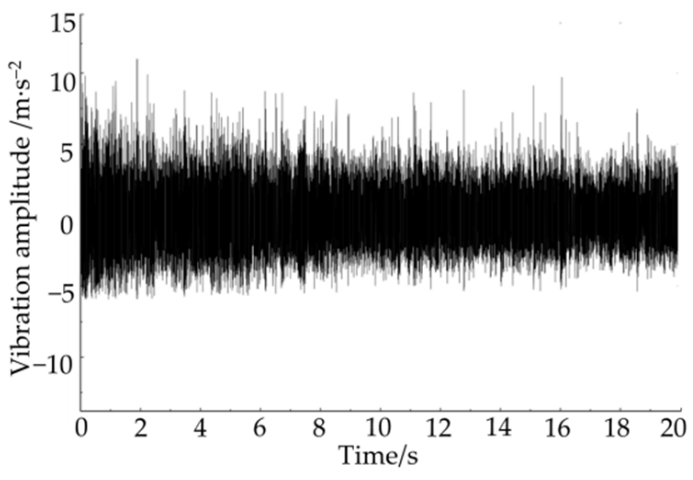

(a)

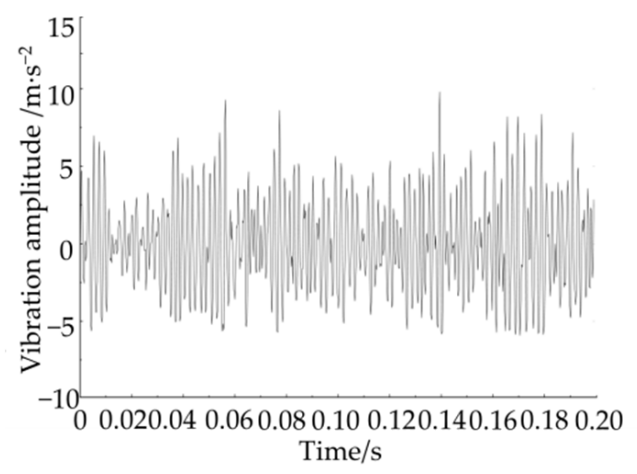

(b)

Figure 15. Vibration time domain signal waveform: (a) full-range waveform diagram of time-domain signal characteristics; (b) local waveform diagram of time-domain signal characteristics.

The Fourier transform of the vibration time-domain signal was carried out by the linear average method. The aim was to decompose the whole time-domain process into countless equal length small segments of signals, and then add windows. The spectral time and frequency resolution were determined by the selected window length. Assuming that the signal is $x(t)$,

$$
F T=(\tau, f)=\int_{-\infty}^{+\infty} x(t) h(t-\tau) e^{-j 2 \pi f t} d \tau
$$

where $j=\sqrt{-1} ; \tau$ is time shift; $t$ is time; $f$ is frequency, $\mathrm{Hz} ; h(t)$ is window function; and $x(t) h(t-\tau)$ is spectrum. 
The number of Fourier analysis points was 1024 . The uniform rectangular window plus window was adopted, and the DC component was removed. The overlap coefficient was $3 / 4$. The vibration spectrum analysis diagram of the frame before and after optimization was obtained, as shown in Figure 16. The vibration frequency and amplitude corresponding to the first five peak points are shown in Table 4.

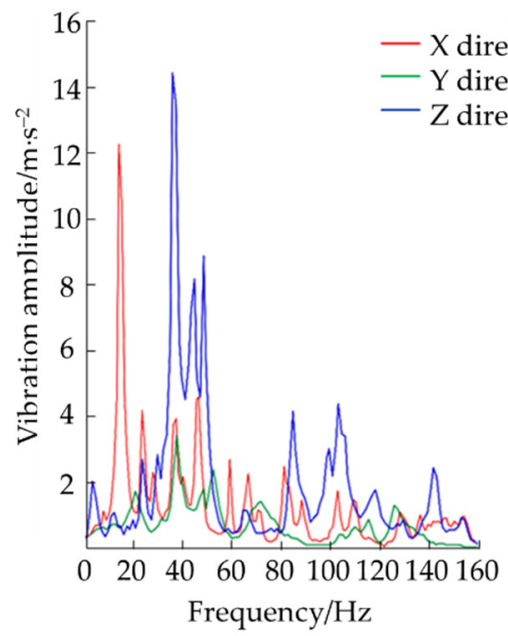

(a)

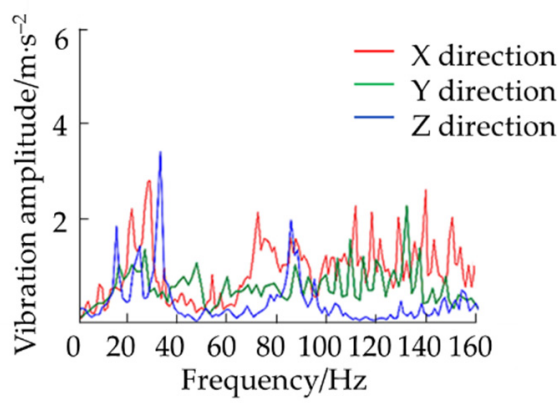

(b)

Figure 16. Spectrum analysis diagram of frame vibration: (a) vibration spectrum analysis diagram of frame before optimization; (b) optimized frame vibration spectrum analysis diagram.

Table 4. Frequency and amplitude corresponding to peak points of test points.

\begin{tabular}{|c|c|c|c|c|c|c|}
\hline \multirow{2}{*}{ Peak Point } & \multicolumn{2}{|c|}{ X Direction } & \multicolumn{2}{|c|}{ Y Direction } & \multicolumn{2}{|c|}{ Z Direction } \\
\hline & Frequency/Hz & Amplitude $/\left(\mathrm{m} / \mathrm{s}^{2}\right)$ & Frequency/Hz & Amplitude $/\left(\mathrm{m} / \mathrm{s}^{2}\right)$ & Frequency/Hz & Amplitude/(m/s $\left.\mathrm{s}^{2}\right)$ \\
\hline A1 & 18.70 & 12.53 & 39.00 & 3.66 & 38.50 & 14.37 \\
\hline $\mathrm{A} 2$ & 47.60 & 4.68 & 54.82 & 2.74 & 50.00 & 9.00 \\
\hline A3 & 22.75 & 4.20 & 22.74 & 1.81 & 45.85 & 8.21 \\
\hline $\mathrm{A} 4$ & 39.85 & 3.96 & 47.60 & 1.75 & 105.82 & 4.28 \\
\hline A5 & 60.00 & 2.83 & 71.25 & 1.60 & 100.50 & 3.06 \\
\hline B1 & 31.45 & 3.06 & 135.50 & 2.36 & 37.60 & 3.17 \\
\hline B2 & 140.20 & 2.88 & 113.47 & 1.83 & 87.55 & 2.00 \\
\hline B3 & 112.72 & 2.60 & 28.40 & 1.79 & 18.26 & 1.97 \\
\hline $\mathrm{B} 4$ & 75.00 & 2.34 & 138.72 & 1.75 & 25.38 & 1.75 \\
\hline B5 & 119.73 & 2.17 & 88.49 & 1.55 & 94.50 & 0.83 \\
\hline
\end{tabular}

Note: A1 A5 are the peak points before frame optimization, and B1 B5 are the peak points after frame optimization.

According to the analysis of Figure 14 and Table 4, before optimization, the violent vibration mainly appeared in the $\mathrm{X}$ and $\mathrm{Z}$ directions, and the vibration amplitude in the $\mathrm{Y}$ direction was low. After optimization, the vibration amplitude of each peak point in the three directions was significantly lower than that before optimization, among which the vibration amplitude of the maximum peak point decreased by $75.56 \%$ in the $X$ direction, $35.52 \%$ in the $\mathrm{Y}$ direction, and $77.94 \%$ in the $\mathrm{Z}$ direction. The results showed that the vibration amplitude of the frame could be significantly reduced by increasing the fixed beam structure.

\subsection{The Results of Field Experiment}

The results of the field experiment are shown in Table 5. It can be seen that the qualified index of grain distance before optimization was only $82.07 \%$, and its miss index was large. This is mainly due to the large vibration of the frame transmitted to the seeder. Under the action of rolling, collision and friction between the seeds in the seed box, it was not easy to scoop the seeds into the scoop during the filling process. At the same time, 
the vibration during the seed carrying process made the smooth surface and small weight Chinese cabbage seeds bounce in the seed scoop, causing the seeds to fall back to the seed box under the action of gravity before they were sent to the seed box. At the same time, before optimization, the coefficient of variation was large, mainly due to the fact that after the seed was placed into the seed guide tube, the vibration increased the collision and friction effect in the seed guide tube during the seed falling process. After the first seed had not fallen into the seed ditch, the seed reached the seed injection point, and under certain probability conditions, the uniformity of seeding became worse, resulting in an increase in the coefficient of variation. After optimization, the qualified index increased significantly, while the multiples index, miss index, and coefficient of variation decreased. The results indicated that vibration had a greater impact on the seeding performance of the seeding device, and reducing the vibration amplitude of the whole machine by avoiding the resonance between the frame and the engine can effectively improve the seeding quality.

Table 5. Comparison of field test results before and after optimization.

\begin{tabular}{cccccccc}
\hline & \multicolumn{3}{c}{ Before Optimization } & \multicolumn{3}{c}{ After Optimization } \\
\hline $\begin{array}{c}\text { Qualified } \\
\text { Index/\% }\end{array}$ & $\begin{array}{c}\text { Multiples } \\
\text { Index } / \%\end{array}$ & $\begin{array}{c}\text { Miss } \\
\text { Index/\% }\end{array}$ & $\begin{array}{c}\text { Coefficient of } \\
\text { Variation } / \%\end{array}$ & $\begin{array}{c}\text { Qualified } \\
\text { Index } / \%\end{array}$ & $\begin{array}{c}\text { Multiples } \\
\text { Index/\% }\end{array}$ & $\begin{array}{c}\text { Miss } \\
\text { Index } / \%\end{array}$ & $\begin{array}{c}\text { Coefficient of } \\
\text { Variation } / \%\end{array}$ \\
\hline 82.07 & 7.83 & 10.1 & 23.55 & 88.63 & 6.25 & 5.12 & 15.71 \\
\hline
\end{tabular}

The vibration of the frame of such a hand-held seeding device has a great impact on the human body. On the basis of the research in this paper, the methods of human vibration measurement and human-computer interaction will be further studied. This study provides a reference for vibration characteristic analysis and vibration reduction design of the same type of hand-held seeder and micro-tiller equipped with a power device, and provides a design basis for reducing the vibration of agricultural machinery frame.

\section{Conclusions}

Based on the combination of the modal analysis and modal test, the vibration characteristics of the vegetable precision seeder frame were studied, and its optimization and improvement were carried out. The conclusions of this study were as follows:

By comparing and analyzing the frequency and modal shapes of finite element modal analysis and modal test of the frame, it showed that the established finite element model was accurate and reliable, which provided an effective method for later vibration reduction optimization design. According to the resonance theory, the coupling between the main frequency of engine vibration $(11.25 \mathrm{~Hz})$ and the first-order natural frequency $(11.08 \mathrm{~Hz})$ of the frame was the main cause of the frame vibration. In order to improve the firstorder natural frequency, it was proposed to increase the fixed beam structure and carry out the influence law of the fixed beam structure parameters and installation size on the natural frequency. After optimization, the first-order natural frequency of the frame was increased from $11.08 \mathrm{~Hz}$ to $15.04 \mathrm{~Hz}$, which effectively avoided the engine excitation frequency and avoided the occurrence of resonance. In order to verify the optimized effect, the vibration acceleration test of the frame measuring point was carried out. The maximum peak vibration amplitude of the frame is significantly reduced after optimization and improvement, in which the $X$ direction was reduced by $75.56 \%$, the $Y$ direction was reduced by $35.52 \%$, and the $Z$ direction was reduced by $77.94 \%$. In order to further explore the effect of the optimized frame on seeding, a seeding performance comparison test, before and after frame optimization, was carried out. The results showed that the qualified index of sowing increased after optimization, while the multiples index, miss index, and coefficient of variation decreased, which effectively improved the uniformity and stability of seeding.

In the field of agricultural machinery, research is mainly to realize specific functions, and the harm caused by the vibration is often ignored. Severe vibration not only leads to detrimental working effects on agricultural machinery, but also makes mechanical 
parts invalid and people's handling comfort worse. This study provides an effective method to locate the parts prone to failure when resonance occurs from the perspective of the combination of theoretical analysis and experiment, which expands the idea for the traditional research that only pays attention to the function and ignores the harmfulness of resonance. At the same time, this study avoids the problem of greatly changing the mechanical structure to reduce the resonance in traditional research and effectively reduce the resonance of agricultural machinery from the perspective of simplified design.

Author Contributions: Conceptualization, J.W. (Jinwu Wang) and C.X.; methodology, C.X. and J.W. (Jinfeng Wang); software, Y.X.; investigation, H.T. and J.W. (Jinfeng Wang); resources, J.W. (Jinwu Wang) and H.T.; data curation, H.T.; writing-original draft preparation, C.X. and H.T.; writingreview and editing, J.W. (Jinwu Wang), Q.W., W.Z., and H.T.; visualization, C.X.; supervision, H.T. and Q.W.; funding acquisition, J.W. (Jinwu Wang) and H.T. All authors have read and agreed to the published version of the manuscript.

Funding: This research was funded by the National Natural Science Foundation of China (NSFC), grant number: 31901414; Natural Science Foundation of Heilongiiang Province of China for Excellent Youth Scholars, grant number: YQ2021E003; and the Young Talents Project of Northeast Agricultural University, grant number: 19QC41.

Institutional Review Board Statement: Not applicable.

Informed Consent Statement: Not applicable.

Data Availability Statement: All data are presented in this article in the form of figures and tables.

Conflicts of Interest: The authors declare no conflict of interest.

\section{References}

1. Guangcai, H.; Fei, L.; Yanhong, W.; Wei, W. Stability analysis of an axially moving free-free beam. J. Mech. Sci. Technol. 2020, 34, 1821-1829. [CrossRef]

2. Li, J.Y.; Lan, Y.B.; Zhou, Z.Y.; Zeng, S.; Huang, C.; Yao, W.X.; Zhang, Y.; Zhu, Q.Y. Design and test of operation parameters for rice air broadcasting by unmanned aerial vehicle. Int. J. Agric. Biol. Eng. 2016, 9, 24-32. [CrossRef]

3. Moeenfard, H.; Mojahedi, M.; Ahmadian, M.T. A homotopy perturbation analysis of nonlinear free vibration of Timoshenko microbeams. J. Mech. Sci. Technol. 2011, 25, 557. [CrossRef]

4. Zhang, X.; Li, C.; Li, J.; Zou, M. Mathematic vibration model of spade punch planter of maize. Nongye Jixie Xuebao/Trans. Chin. Soc. Agric. Mach. 2014, 45, 88-93. [CrossRef]

5. Li, Q.; Zhu, Y.; Xu, D.; Hu, J.; Min, W.; Pang, L. A negative stiffness vibration isolator using magnetic spring combined with rubber membrane. J. Mech. Sci. Technol. 2013, 27, 813-824. [CrossRef]

6. Qin, Z.; Wu, Y.T.; Eizad, A.; Lee, K.H.; Lyu, S.K. Design and evaluation of two-stage planetary gearbox for special-purpose industrial machinery. J. Mech. Sci. Technol. 2019, 33, 5943-5950. [CrossRef]

7. Moon, S.I.; Cho, I.J.; Yoon, D. Fatigue life evaluation of mechanical components using vibration fatigue analysis technique. J. Mech. Sci. Technol. 2011, 25, 631-637. [CrossRef]

8. Sorokin, V.; Blekhman, I. On the stochastic resonance phenomenon in parametrically excited systems. Eur. J. Appl. Math. 2019, 30, 986-1003. [CrossRef]

9. Winton, D.M.; Dowling, D.R. Modal content of heavy-duty diesel engine block vibration. SAE Tech. Pap. 1997, 106, $2802-2811$.

10. Tong, J.; Zeng, B.; Chen, D.; Quan, L.; Zhang, S. Finite element modal analysis of the frame of corn stubble-collector. Adv. Mater. Res. 2012, 430-432, 1072-1075. [CrossRef]

11. Fouzi, M.S.M.; Jelani, K.M.; Nazri, N.A.; Sani, M.S.M. Finite element modelling and updating of welded thin-walled beam. Int. J. Automot. Mech. Eng. 2018, 15, 5874-5889. [CrossRef]

12. Li, X.J.; Chen, L.Q. Modal analysis of coupled vibration of belt drive systems. Appl. Math. Mech. (Engl. Ed.) 2008, 29, 9-13. [CrossRef]

13. Taghizadeh-Alisaraei, A.; Ghobadian, B.; Tavakoli-Hashjin, T.; Mohtasebi, S.S.; Rezaei-asl, A.; Azadbakht, M. Characterization of engine's combustion-vibration using diesel and biodiesel fuel blends by time-frequency methods: A case study. Renew. Energy 2016, 95, 422-432. [CrossRef]

14. Yao, Y.; Du, Y.; Zhu, Z.; Mao, E.; Song, Z. Vibration characteristics analysis and optimization of corn combine harvester frame using modal analysis method. Nongye Gongcheng Xuebao/Trans. Chin. Soc. Agric. Eng. 2015, 31, 46-53. [CrossRef]

15. Yan, K.; Cheng, G.D.; Wang, B.P. Topology optimization of damping layers in shell structures subject to impact loads for minimum residual vibration. J. Sound Vib. 2018, 431, 226-247. [CrossRef]

16. Liu, F.; Yang, Y.; Zeng, Y.; Liu, Z. Bending diagnosis of rice seedling lines and guidance line extraction of automatic weeding equipment in paddy field. Mech. Syst. Signal Process. 2020, 142, 106791. [CrossRef] 
17. Stanford, B.; Beran, P.; Bhatia, M. Aeroelastic topology optimization of blade-stiffened panels. J. Aircr. 2014, 51, 938-944. [CrossRef]

18. Jiang, Y.; Liao, Y.; Qin, C.; Guan, Z.; Liao, Q. Vibration analysis and improvement for frame of 4SY-2.9 typed rape windrower. Nongye Gongcheng Xuebao/Trans. Chin. Soc. Agric. Eng. 2017, 33, 53-60. [CrossRef]

19. Liu, B.; Jiang, H.L. Finite element modal analysis of S385 diesel engine block. Appl. Mech. Mater. 2014, 490-491, 504-509. [CrossRef]

20. Jalali, H.; Parvizi, F. Experimental and numerical investigation of modal properties for liquid-containing structures. J. Mech. Sci. Technol. 2012, 26, 1449-1454. [CrossRef]

21. Ma, L.; Huang, X.; Song, Z.; Mao, E.; Liang, F. Finite Element Analysis and Experiment on Corn Harvester Frame Based on Load Characteristics. Nongye Jixie Xuebao/Trans. Chin. Soc. Agric. Mach. 2018, 49, 288-294. [CrossRef]

22. Chen, M.; Cheng, X.; Jia, X.; Zhang, L.; Li, Q. Optimization of operating parameter and structure for corn ear picking device by bionic breaking ear hand. Nongye Gongcheng Xuebao/Trans. Chin. Soc. Agric. Eng. 2018, 34, 15-22. [CrossRef]

23. Li, Y.; Li, Y.; Xu, L.; Hu, B.; Wang, R. Structural parameter optimization of combine harvester cutting bench. Nongye Gongcheng Xuebao/Trans. Chin. Soc. Agric. Eng. 2014, 30, 30-37. [CrossRef]

24. Zhou, X.; Chen, P.; Wang, Y. Finite element calculation and experiment comparison about masonry-infilled frame structure considering connection ways between infill wall and frame. World Earthq. Eng. 2015, 31, 188-195.

25. Maia, N.M.M.; Silva, J.M.M. Modal analysis identification techniques. Philos. Trans. R. Soc. A Math. Phys. Eng. Sci. 2001, 359, 29-40. [CrossRef]

26. Kim, K.; Lee, Y.S. Dynamic test and fatigue life evaluation of compressor blades. J. Mech. Sci. Technol. 2014, $28,4049-4056$. [CrossRef]

27. Wu, Y.H.; Wang, F. Modal analysis of a semi-trailer frame based on ansys workbench. In Proceedings of the 2011 Fourth International Conference on Information and Computing, Phuket, Thailand, 25-27 April 2011. ICIC 2011.

28. Zhao, X.; Zhao, T.; Xu, X.; Zhao, Y.; Li, Z. Vibration Characteristics Analysis and Experimental Validation of 3-P(4S) Parallel Platform. Nongye Jixie Xuebao/Trans. Chin. Soc. Agric. Mach. 2018, 49, 419-426. [CrossRef]

29. Li, X.; Shen, B.; Cai, Y.; Jiang, Y.; Zhang, K. Model correlation between calculated and experimental mode of 4105 diesel engine crankshaft. Nongye Gongcheng Xuebao/Trans. Chin. Soc. Agric. Eng. 2011, 27, 51-55. [CrossRef]

30. Wang, L.; Wang, Q.; Zhang, W. Optimization design of towbarless aircraft tractor frame based on ANSYS workbench. Appl. Mech. Mater. 2013, 268, 921-925. [CrossRef]

31. Cai, L.; Ma, S.; Zhao, Y.; Liu, Z.; Yang, W. Finite element modeling and modal analysis of heavy-duty mechanical spindle under multiple constraints. Jixie Gongcheng Xuebao/J. Mech. Eng. 2012, 3, 165-173. [CrossRef]

32. Zhu, M.; He, Z.; Xu, L.; Li, Z. Mode analysis of car-body and its correlative research shape. Nongye Jixie Xuebao/Trans. Chin. Soc. Agric. Mach. 2004, 3, 13-19.

33. Xu, L.; Li, Y.; Sun, P.; Pang, J. Vibration measurement and analysis of tracked-whole feeding rice combine harvester. Nongye Gongcheng Xuebao/Trans. Chin. Soc. Agric. Eng. 2014, 30, 49-55. [CrossRef]

34. Jiangtao, J.; Kaikang, C.; Xin, J.; Zhaoyang, W.; Baoqiong, D.; Jingyuan, F.; Xiaojun, L. High-efficiency modal analysis and deformation prediction of rice transplanter based on effective independent method. Comput. Electron. Agric. 2020, 168, 105126. [CrossRef]

35. Hu, W.; Wang, F.; Cao, D.; Chen, J.; Feng, J. Quantitative validation of the analytical mode shapes of a beam-like structure with a Z-shaped configuration. J. Mech. Sci. Technol. 2019, 33, 2059-2065. [CrossRef] 